\title{
Loss of Synaptic Tagging in the Anterior Cingulate Cortex after Tail Amputation in Adult Mice
}

\author{
Ming-Gang Liu, ${ }^{1,2,3 \star}$ Qian Song, ${ }^{1,2 \star}$ and ${ }^{\circledR}$ Min Zhuo ${ }^{1,2}$ \\ ${ }^{1}$ Center for Neuron and Disease, Frontier Institute of Science and Technology, Xi'an Jiaotong University, Xi' an 710049, China, ${ }^{2}$ Department of Physiology, \\ Faculty of Medicine, University of Toronto, Toronto, Ontario M5S 1A8, Canada, and ${ }^{3}$ Department of Anatomy and Physiology, Institute of Medical \\ Sciences, Shanghai Jiao Tong University School of Medicine, Shanghai 200025, China
}

Anterior cingulate cortex (ACC) is known to play important roles in key brain functions such as pain perception, cognition, and emotion. Different forms of homosynaptic plasticity such as long-term potentiation (LTP) and long-term depression have been studied in ACC synapses. However, heterosynaptic plasticity such as synaptic tagging has not been reported. Here, we demonstrate synaptic tagging in the ACC of adult male mice by using a 64-channel multielectrode array recording system. Weak theta burst stimulation (TBS), normally inducing early-phase LTP or No-LTP in most of the activated channels, produced late phase-LTP (L-LTP) in a majority of channels when a strong TBS was applied earlier to a separate input within a certain time window. Similar to hippocampus, synaptic tagging in the ACC depends on the synthesis of new proteins. Tail amputation-induced peripheral injury caused a loss of this heterosynaptic L-LTP and occluded strong TBS-evoked L-LTP as well. Together, we provide the first report of the synaptic tagging-like phenomenon in the ACC of adult mice, and the loss of synaptic tagging to amputation may contribute to injury-related cognitive changes and phantom limb sensation and pain.

Key words: amputation; anterior cingulate cortex; long-term potentiation; mice; phantom pain; synaptic tagging

\section{Significance Statement}

ACC is an important cortical region involved in many brain functions. Previous studies have dissected the molecular mechanism of multiple types of homosynaptic plasticity of ACC synapses. Here, we report a novel form of heterosynaptic plasticity occurring in the ACC. This newly identified, protein synthesis-dependent neocortical synaptic tagging is sensitive to peripheral tail amputation injury and may provide basic mechanisms for synaptic pathophysiology of phantom pain and related cognitive changes.

\section{Introduction}

Long-term potentiation (LTP), an activity-dependent longlasting increase of synaptic efficacy caused by high-frequency stimulation, has been well established as a cellular model of information storage in the brain (Bliss and Collingridge, 2013; Takeuchi et al., 2014). Multiple lines of evidence suggest that LTP has at least two mechanistically distinct temporal phases: protein synthesis-independent early-phase LTP (E-LTP) and protein

Received Feb. 19, 2018; revised July 21, 2018; accepted July 24, 2018.

Author contributions: M.-G.L. and Q.S. wrote the first draft of the paper; M.Z. edited the paper. M.Z. designed research; M.-G.L. and Q.S. performed research; Q.S. analyzed data; M.-G.L. and M.Z. wrote the paper.

This work was supported by Grants from the EJLB-CIHR Michael Smith Chair in Neurosciences and Mental Health, Canada Research Chair, CIHR Operating Grant (MOP-124807) and Project Grant (PJT-148648), the Azrieli Neurodevelopmental Research Program and Brain Canada to M.Z., and the National Natural Science Foundation of China (Grants 31500834 and 31771157 ) to M.-G.L.

The authors declare no competing financial interests.

${ }^{*}$ M.-G.L. and Q.S. contributed equally to this work.

Correspondence should be addressed to Min Zhuo, Department of Physiology, Faculty of Medicine, University of Toronto, 1 King's College Circle, Toronto, 0N M5S 1A8, Canada. E-mail: minzhu010@gmail.com.

DOI:10.1523/JNEUROSCI.0444-18.2018

Copyright $\odot 2018$ the authors $\quad 0270-6474 / 18 / 388060-11 \$ 15.00 / 0$ synthesis-dependent late-phase LTP (L-LTP; Chen et al., 2014a, 2017; Park et al., 2016). Interestingly, E-LTP and L-LTP can interact with each other in a 'synaptic tagging-like' manner, where a weak tetanus inducing E-LTP sets a "tag", which can capture the plasticity-related proteins (PRPs) synthesized following the strong tetanus inducing L-LTP (Frey and Morris, 1997, 1998; Reymann and Frey, 2007). Consequently, a weak stimulus can induce L-LTP if it is preceded or followed by a strong tetanus given to a separate, independent pathway that converges into the same neuronal population. The synaptic tagging hypothesis has been validated by increasing numbers of studies (Young and Nguyen, 2005; Alarcon et al., 2006; Ishikawa et al., 2008; Shires et al., 2012; Sharma et al., 2017) and is believed to play important roles in long-term memory storage/allocation (Wang et al., 2010; Redondo and Morris, 2011; Rogerson et al., 2014) as well as memory deficits in neurodegenerative diseases such as the Alzheimer's disease (Sharma et al., 2015; Li et al., 2017).

Anterior cingulate cortex (ACC) is an important forebrain structure involved in many higher brain functions, such as learning, memory, pain, and emotion processing (Frankland et al., 
A

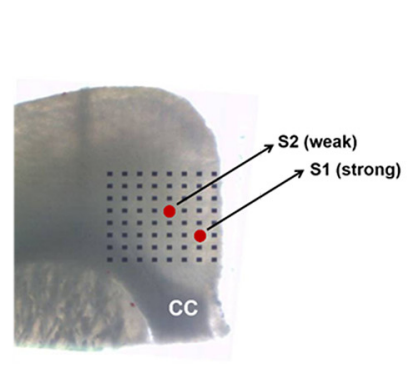

D
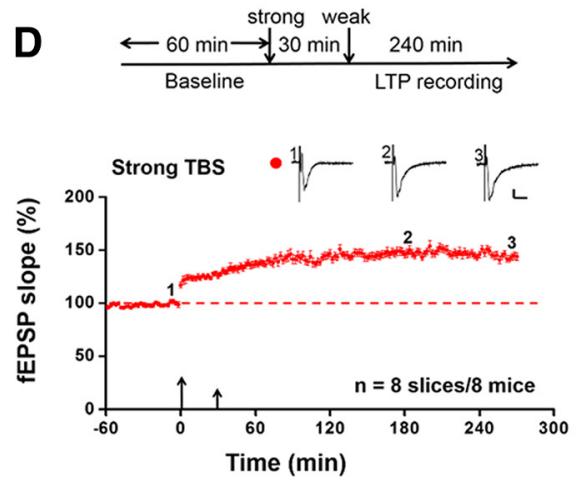

B

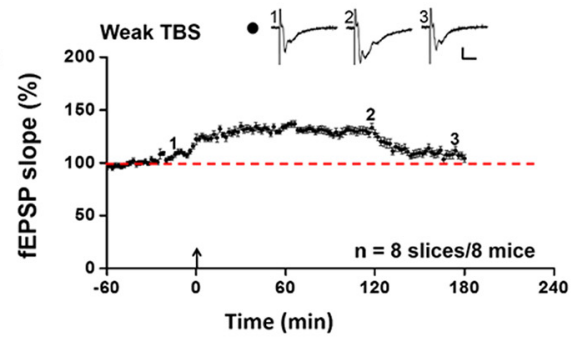

E

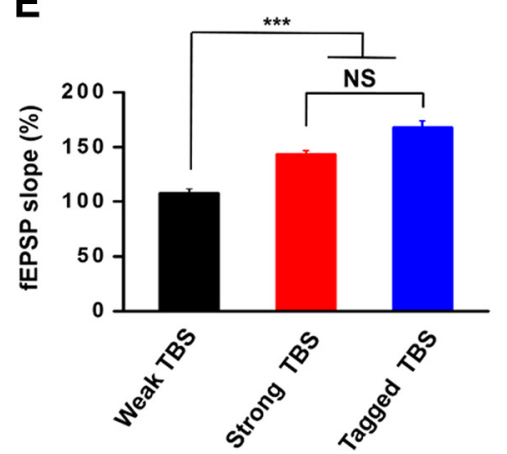

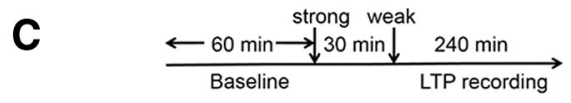

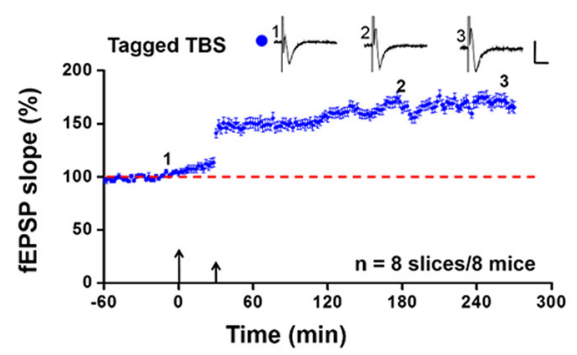

$\mathbf{F}$
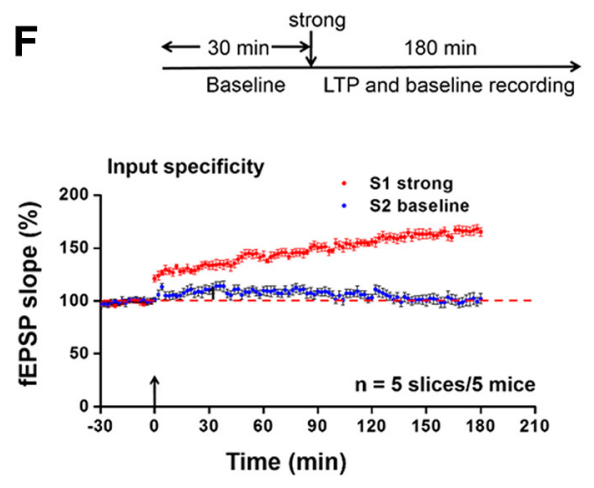

Figure 1. Synaptic tagging occurs in the adult mouse ACC. $A$, Light microscopy photograph showing the location of the MED64 probe relative to one ACC slice. We applied electrical stimulation separately to two distinct inputs as shown by the two red dots in the picture. The S1 stimulation site received strong TBS in the superficial layer, whereas the S2 site was given a weak TBS in the deep layer of ACC (see Materials and Methods for the details of the protocols). CC, Corpus callosum. B, Summarized plot of the fEPSP slope demonstrates the induction of E-LTP by weak TBS alone that gradually decayed to the baseline within $3 \mathrm{~h}$. C, Summarized plot of the fEPSP slope demonstrates the induction of L-LTP by weak TBS if preceded, 30 min earlier, by a strong TBS (i.e., tagged TBS). Tagged TBS-evoked L-LTP lasts for at least $4 \mathrm{~h}$. D. Summarized plot of the fEPSP slope shows the induction of persistent L-LTP by strong TBS alone that lasts for $4.5 \mathrm{~h}$. $\boldsymbol{E}$, Bar histogram showing quantified data within last $10 \mathrm{~min}$ of the LTP recording for weak TBS alone, strong TBS alone, and tagged TBS. The magnitude of tagged TBS-induced L-LTP did not differ from that of strong TBS alone. $\boldsymbol{F}$, Pooled data showing that delivery of strong TBS onto $\mathbf{S 1}$ pathway had no effect on the baseline responses in another $\mathbf{2}$ pathway. $\boldsymbol{B}-\boldsymbol{D}, \boldsymbol{F}$, Schematic diagram of the recording procedure for each experiment is shown at the top of the plot. Insets, Representative fEPSP traces taken at the time points indicated by numbers in the graph. Calibration: $100 \mu \mathrm{V}, 10 \mathrm{~ms}$. Large arrows indicate starting point of strong TBS application; small arrows mark the time point of weak TBS delivery. ${ }^{* *} p<0.001$ versus weak TBS. NS, No significance. Error bars represent SEM.

2004; Bliss et al., 2016; Zhuo, 2016; Chen et al., 2018; Ko et al., 2018). Previous work have shown that excitatory synapses in the ACC are highly plastic, being capable of exhibiting multiple types of synaptic plasticity, including postsynaptic LTP (Zhao et al., 2005; Liu and Zhuo, 2014a), presynaptic LTP (Koga et al., 2015, 2017), and long-term depression (LTD; Wei et al., 1999; Chiou et al., 2012; Kang et al., 2012). Additionally, we demonstrate that ACC synapses can equally exhibit a form of L-LTP, which is dependent on protein kinase $\mathrm{M} \zeta(\mathrm{PKM} \zeta$ ) activation (Li et al., 2010) and AMPA receptor phosphorylation (Song et al., 2017). However, it is unclear whether synaptic tagging also occurs in the ACC.

Amputation-induced limb deafferentation has been documented to model the pathological tissue injury conditions in patients with phantom limb pain (Flor et al., 2006). Our previous work demonstrates that peripheral amputation could result in long-lasting plastic changes in excitatory synaptic transmission in the rodent forebrain structures, including ACC and insular cortex (Wei and Zhuo, 2001; Zhuo, 2012). One common synaptic dysfunction caused by amputation is the loss of LTD in the cortex (Wei et al., 1999; Kang et al., 2012; Liu and Zhuo, 2014b). However, little information is now available concerning the effect of amputation on LTP inducibility and associativity in the brain. In the present study, we used a 64-channel multielectrode dish (MED64) recording system (Liu et al., 2013a; Liu and Zhuo, 2014a) to first investigate the induction properties of E-LTP and L-LTP in the acute mouse ACC slices by two different types of conditioning stimulus, weak theta burst stimulation (TBS) and strong TBS. We found that weak TBS, which normally induces E-LTP in most of the activated channels, could cause L-LTP when a strong TBS is delivered before the weak TBS within a certain time window, indicating the occurrence of synaptic tagging-like phenomenon in the ACC. We then demonstrate that tail amputation resulted in a loss of this heterosynaptic interaction of ACC LTP, possibly due to the occlusion of strong TBS-evoked L-LTP induction in the amputated slices.

\section{Materials and Methods}

Animals. The experiments were performed on male C57BL/6 mice (8-10 weeks old, Charles River Laboratories). All animals were fed in groups of three per cage under standard laboratory conditions (12 h light/dark, temperature $22-26^{\circ} \mathrm{C}$, air humidity $55-60 \%$ ) with ad libitum water and mice chow. All works were conducted according to the policy and regulation for the care and use of laboratory animals approved by Xi'an Jiaotong University or University of Toronto.

Slice preparation. The general procedures for making the ACC slices are similar to those described previously (Song et al., 2017; Ko et al., 2018). Briefly, mice were anesthetized with gaseous isoflurane and decapitated. The whole brain was rapidly removed and immersed into a cold bath of oxygenated (equilibrated with $95 \% \mathrm{O}_{2}$ and $5 \% \mathrm{CO}_{2}$ ) artificial CSF (ACSF) containing the following (in mM): $124 \mathrm{NaCl}, 2.5 \mathrm{KCl}, 1.0$ $\mathrm{NaH}_{2} \mathrm{PO}_{4}, 1 \mathrm{MgSO}_{4}, 2 \mathrm{CaCl}_{2}, 25 \mathrm{NaHCO}_{3}$, and 10 glucose, pH 7.357.45. This ACSF was used throughout the experiment. After cooling for 1-2 min, appropriate portions of the brain were then trimmed and the remaining brain block was glued onto the ice-cold stage of a vibrating 

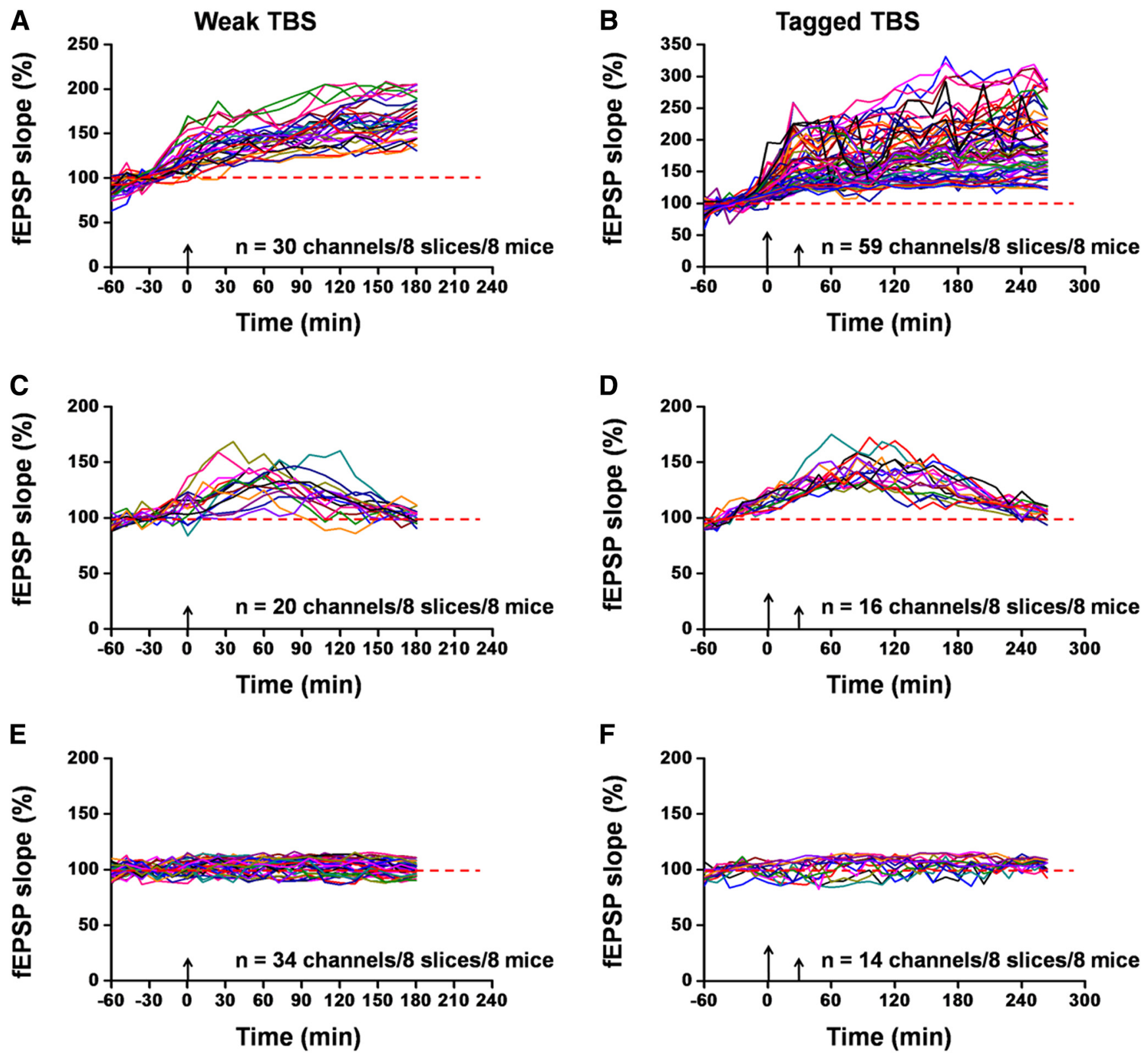

Figure 2. Individual data presentation of synaptic tagging recording in the ACC. $A, C, E$, Individual data of L-LTP-, E-LTP-, and No-LTP-showing channels for the $S 2$ input receiving weak TBS alone. Totally, 30 channels underwent L-LTP, while 20 channels showed E-LTP. There were 34 channels that did not exhibit any potentiation ( $n=8$ slices $/ 8$ mice). B, D, F, Individual data of L-LTP-, E-LTPand No-LTP-showing channels for the S2 input receiving weak TBS at 30 min after a strong TBS (i.e., tagged TBS). Among the eight slices analyzed, 59 , 16, and 14 channels showed L-LTP, E-LTP, and No-LTP, respectively. Tagged TBS induced more L-LTP-showing channels than weak TBS, confirming the occurrence of synaptic tagging in the ACC. Large arrows indicate starting point of strong TBS application; small arrows mark the time point of weak TBS delivery.

tissue slicer (Leica, VT1000S). Then three coronal ACC slices $(300 \mu \mathrm{m})$ were obtained at the level of corpus callosum connection and placed in a submerged recovery chamber with oxygenated $\left(95 \% \mathrm{O}_{2}, 5 \% \mathrm{CO}_{2}\right)$ ACSF at room temperature for at least $2 \mathrm{~h}$.

Multichannel field potential recordings. A commercial 64-channel recording system (MED64, Panasonic Alpha-Med Sciences) was used for multichannel field potential recordings in this study. Procedures for preparation of the MED64 probe and extracellular field potential recordings were similar to those described previously (Liu et al., 2013a,b; Liu and Zhuo, 2014b). Before use, the surface of the MED64 probe (MEDP515A, $8 \times 8$ array, interpolar distance $150 \mu \mathrm{m}$; Panasonic) was treated with $0.1 \%$ polyethyleneimine (Sigma-Aldrich) in $25 \mathrm{~mm}$ borate buffer, $\mathrm{pH} 8.4$, overnight at room temperature. Then, the probe surface was rinsed three times with sterile distilled water. After incubation, one slice was positioned on the MED64 probe in such a way that the whole array of the electrodes could cover the different layers of the ACC (Fig. 1A). Once the slice was settled, a fine mesh anchor (Warner Instruments) was carefully positioned to ensure slice stability during recording. The slice was continuously perfused with oxygenated, fresh ACSF at the rate of 2-3 $\mathrm{ml} / \mathrm{min}$ with the aid of a peristaltic pump (Minipuls 3, Gilson) throughout the entire experimental period.

After a $10-15$ min recovery period, one of the 64 planar microelectrodes was selected for stimulation by visual observation through a charge-coupled device camera (DP70, Olympus) connected to the inverted microscope. For test stimulation, constant current pulses $(0.2 \mathrm{~ms}$ in duration) generated by the data acquisition software (Mobius, Panasonic Alpha-Med Sciences) were applied to either deep layer (layer V-VI, for S2-weak input) or superficial layer (layer I-III, for S1-strong input) of the ACC slice at $0.008 \mathrm{~Hz}$. The intensity of the stimuli was $\sim 40-60 \%$ of the intensity that induced the maximal field EPSPs (fEPSPs). The fEPSPs evoked at both superficial layer and deep layer of the ACC were amplified by a 64 -channel amplifier, displayed on the monitor screen, and stored 


\section{A TBS: S1-strong}

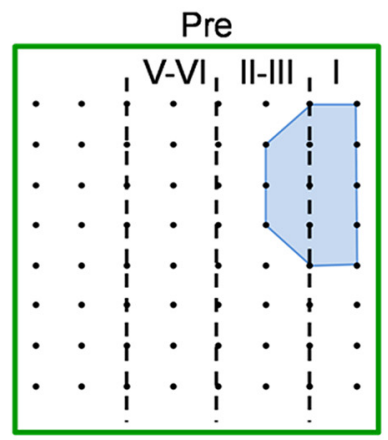

Post

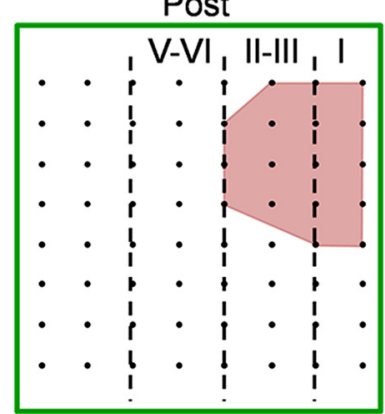

C TBS: S2-weak

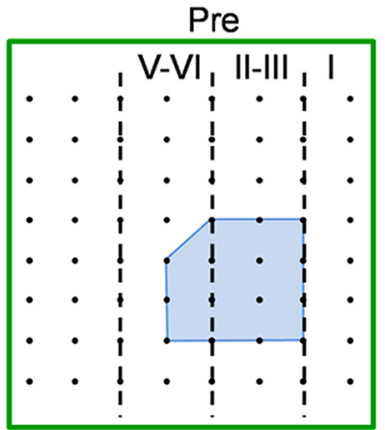

Post

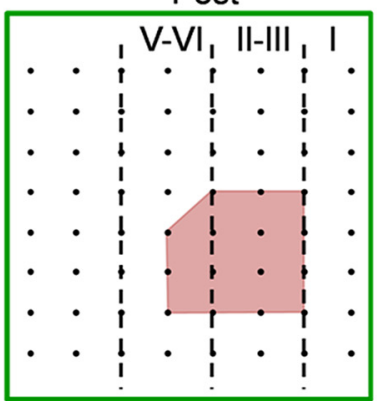

B $\mathbf{n}=\mathbf{8}$ slices $/ 8$ mice

Pre

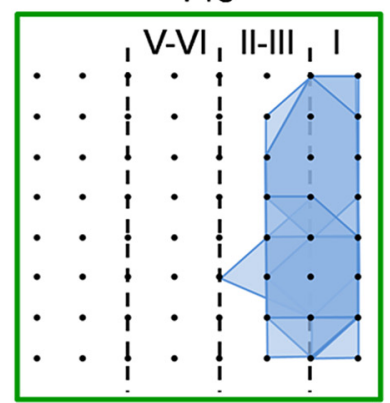

Post

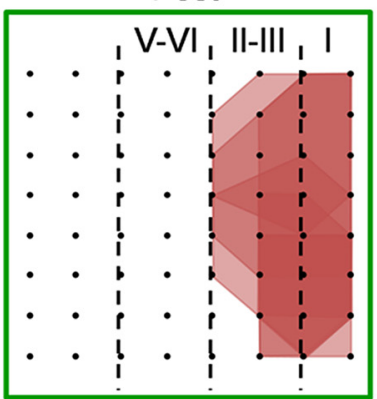

D $\quad \mathrm{n}=\mathbf{8}$ slices $/ 8$ mice

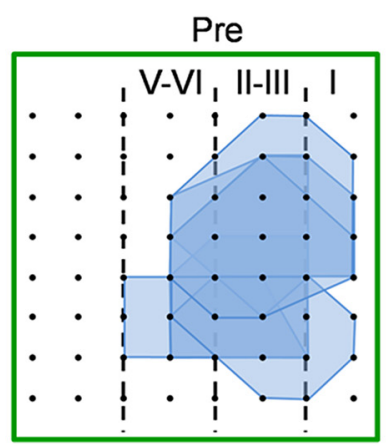

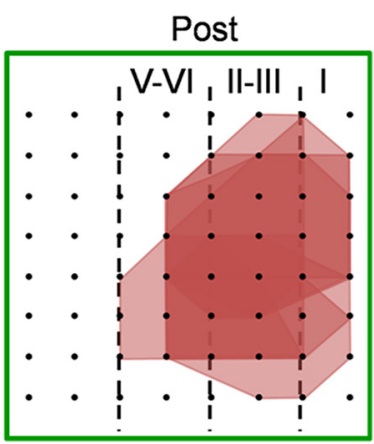

Figure 3. No recruitment of new responses after synaptic tagging in the ACC. $A$, Polygonal diagrams of the channels that were activated in the baseline state (blue, pre) and at $4.5 \mathrm{~h}$ after strong TBS of the S1 site (red, post) in one slice. Black dots represent the 64 channels in the MED64 system. Vertical lines indicate the layers in the ACC slice. B, Pooled data of eight slices from eight mice for the spatial analysis performed as in $A$. C, Polygonal diagrams of the channels that were activated in the baseline state (blue, pre) and at $4 \mathrm{~h}$ after weak TBS (preceded by strong TBS, i.e., tagged TBS, red, post) in one slice. $\boldsymbol{D}$, Pooled data of eight slices from eight mice for the spatial analysis performed as in $\boldsymbol{C}$. Delivery of strong TBS resulted in an enlargement of the activation area, whereas tagged TBS did not recruit new synaptic responses in the ACC.

on the hard disk of a microcomputer for off-line analysis. Stable baseline responses were first recorded until the variation is $<5 \%$ in most of the active channels within $1 \mathrm{~h}$. For E-LTP induction, a weak TBS protocol (5 bursts at $5 \mathrm{~Hz}$, four pulses at $100 \mathrm{~Hz}$ for each burst) was given at the deep layer (Fig. $1 A$, S2 weak) with the same stimulation intensity as the baseline. For L-LTP induction, a strong TBS protocol $(5$ bursts at $5 \mathrm{~Hz}$, repeated 5 times at $10 \mathrm{~s}$ intervals, four pulses at $100 \mathrm{~Hz}$ for each burst; Chen et al., 2014a) was delivered at the superficial layer (S1 strong; Fig. $1 A$ ). The interval between strong TBS and weak TBS varied from $30 \mathrm{~min}$ to $2 \mathrm{~h}$. After TBS, the test stimulus was repeatedly delivered as described above once every $2 \mathrm{~min}$ for $4-4.5 \mathrm{~h}$ to monitor the time course of cingulate LTP. In some experiments, we applied anisomycin ( $25 \mu \mathrm{M}$; Tocris Cookson) from 20 min before until $20 \mathrm{~min}$ after strong TBS to examine the protein synthesis dependence of heterosynaptic tagging in the ACC.

Tail amputation. To determine whether peripheral injury could influence the synaptic tagging in the ACC, we performed tail amputation on adult male mice as described previously (Kang et al., 2012; Liu and Zhuo, $2014 \mathrm{~b}$ ). After anesthesia with gaseous isoflurane, the mouse was put in a box where a $2.5 \mathrm{~cm}$ length of the tail tip was removed using surgical scissors. A drop of Krazy Glue was used to stop bleeding. Amputated animals did not exhibit any neurological deficits when returned to the home cage. Procedure was executed with caution to minimize handlinginduced stress in the mice. In the present study, we performed electrophysiological recordings at 2 weeks after tail amputation based on our previous reports showing an evident plastic change in the ACC at this time point (Wei et al., 1999; Kang et al., 2012; Liu and Zhuo, 2014b).

Experimental design and statistical analysis. In the present study, we mainly used the multielectrode array system to test the possible heterosynaptic interactions between two separate afferent inputs of the ACC pyramidal neurons. To probe the occurrence of synaptic tagging in the ACC, we applied a strong TBS protocol to one site of the superficial layer of the ACC slice while delivering a relatively weak TBS protocol at differ- ent time intervals to the deep layer of the same slice. By analyzing the induction properties of LTP in three categories (No-LTP, E-LTP, and L-LTP) in different conditions, we can determine the inducibility and heterosynaptic associativity of LTP among distinct inputs. We also bath applied the drug anisomycin around the delivery of strong TBS to evaluate the dependence of synaptic tagging on new protein synthesis. Last, we performed similar multisite recordings of LTP in the ACC slices obtained from tail-amputated animals, to see whether synaptic tagging is vulnerable to peripheral injury.

All multichannel electrophysiological data were analyzed off-line by the MED64 Mobius software. For quantification of the LTP data, the initial slope of fEPSPs was measured by taking the rising phase between $10 \%$ and $90 \%$ of the peak response, normalized and presented as a percentage change from the baseline level. We defined LTP in a channel if the response was increased by at least $20 \%$ of baseline during the entire recording period. In some cases, we presented the data of all activated channels according to three major categories: L-LTP, E-LTP, and NoLTP. The number of activated channels, E-LTP-, L-LTP- and No-LTPshowing channels was also counted and the induction ratio in each category was calculated as described previously (Liu et al., 2013b; Liu and Zhuo, 2014a). All data are presented as mean \pm SEM. When necessary, the statistical significance was assessed by two-tailed Student's $t$ test or one-way ANOVA (post hoc Fisher's LSD test) with SigmaPlot software. $p<0.05$ was assumed to be statistically significant.

\section{Results}

Synaptic tagging occurs in the ACC synapses

To explore the possibility of synaptic tagging in the ACC, we used a 64-channel field potential recording system to study the induction probability and properties of E-LTP, L-LTP and their associative interactions in acute ACC slices in vitro (Liu et al., 2013b; 
A
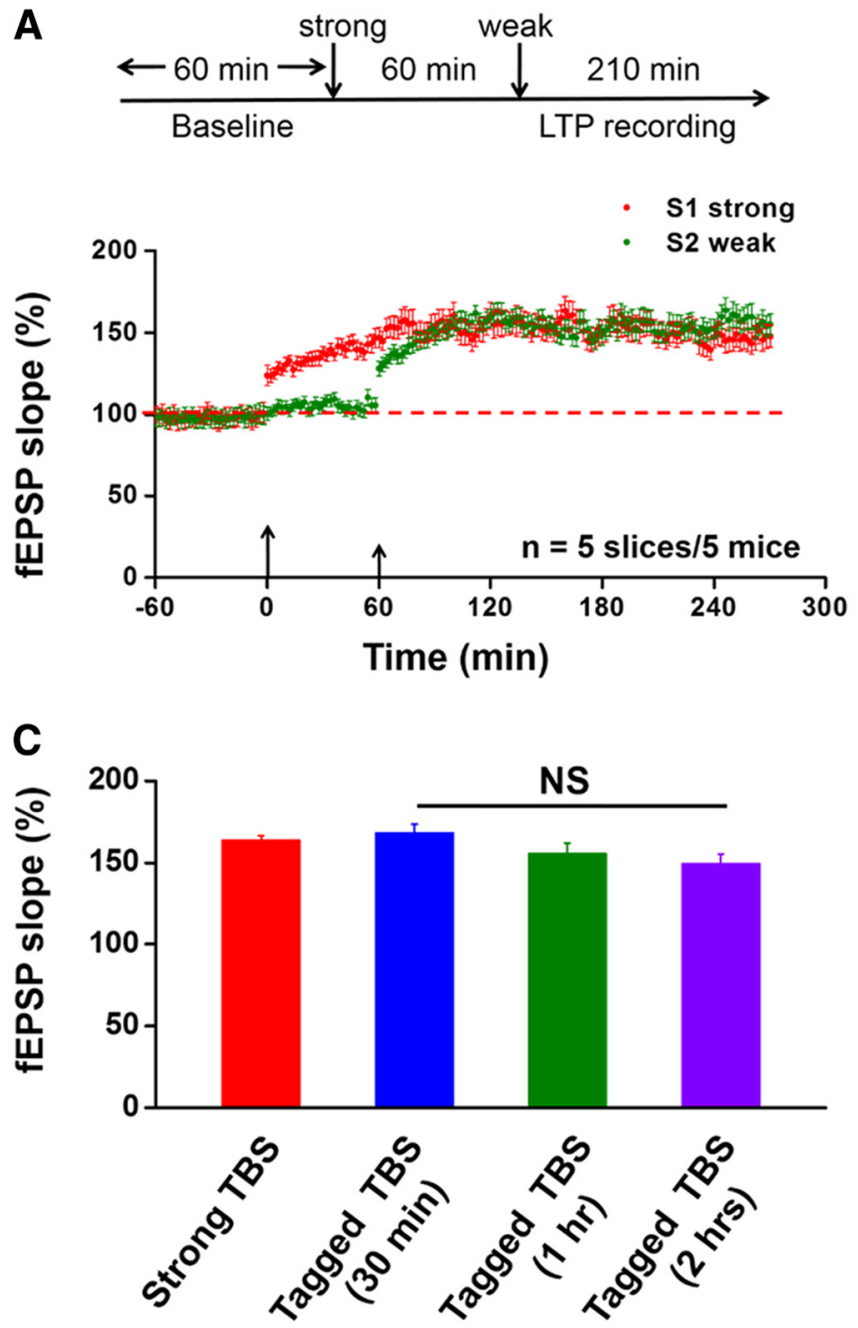

B
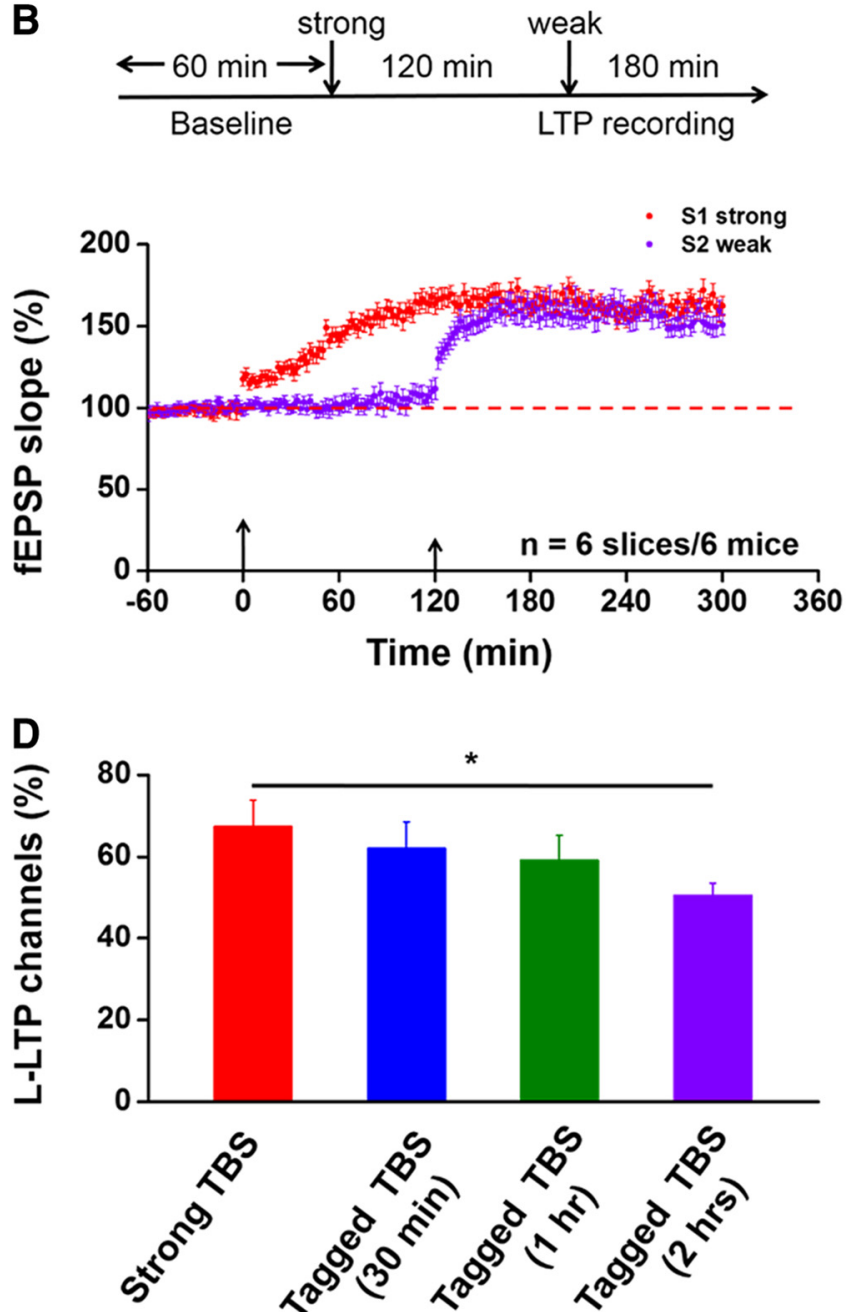

Figure 4. Time window of synaptic tagging in the ACC. $A$, Top, Schematic diagram of the recording procedure. We applied the weak TBS protocol to the $S 2$ site at $1 \mathrm{~h}$ after strong TBS of the $S 1$ site (tagged TBS, $1 \mathrm{~h}$ ). Bottom, Pooled data showed that both strong TBS at S1 site and weak TBS at $S 2$ site could induce L-LTP $(n=5 \mathrm{slices} / 5$ mice). $B$, Top, schematic diagram of the recording procedure. The weak TBS protocol was applied to the 22 site at $2 \mathrm{~h}$ after strong TBS of the S1 site (tagged TBS, $2 \mathrm{~h}$ ). Bottom, Pooled data showed that weak TBS could still benefit from the strong TBS by inducing sustained L-LTP ( $n=6$ slices/6 mice). C, Bar histogram summarizing quantified data within last $10 \mathrm{~min}$ of the L-LTP recording for strong TBS, tagged TBS $30 \mathrm{~min}$, tagged TBS $1 \mathrm{~h}$, and tagged TBS $2 \mathrm{~h}$. NS, No significance. D, Percentage of L-LTP-showing channels among the four groups. Although L-LTP could still be generally induced by weak TBS, the percentage of channels that undergo L-LTP was clearly decreased with $2 \mathrm{~h}$ interval. ${ }^{*} p<0.05$ versus strong TBS. NS, No significance. Large arrows in $\boldsymbol{A}$ and $\boldsymbol{B}$ indicate starting point of strong TBS application; small arrows mark the time point of weak TBS delivery. Error bars represent SEM.

Chen et al., 2014a). For most of the experiments, we separately stimulated two different synaptic inputs in different layers of the ACC (S1, superficial layer; S2, deep layer) and performed simultaneous multichannel fEPSP recordings evoked by these two stimulation sites (Fig. 1A). In the first set of experiments, however, we only delivered a single weak TBS ( 5 trains of burst with 4 pulses at $100 \mathrm{~Hz}$ at $200 \mathrm{~ms}$ interval) to the S2 stimulation site after obtaining stable baseline synaptic responses for at least $1 \mathrm{~h}$. Monitoring of S2 stimulation-evoked synaptic responses revealed that only a short-lasting E-LTP was induced by weak TBS alone, with the potentiation decayed to the baseline within $3 \mathrm{~h}(104.2 \pm 3.5 \%$ of baseline at $3 \mathrm{~h}$ after weak TBS, $n=8$ slices $/ 8$ mice, $t_{(7)}=$ $-1.806, p=0.114$, paired $t$ test; Fig. $1 B)$.

Next, to determine the heterosynaptic interactions between $S 1$ and $\mathrm{S} 2$ sites, we first applied a strong TBS to the $\mathrm{S} 1$ site and $30 \mathrm{~min}$ later, the weak TBS was delivered to S2 site. Interestingly, we found that weak TBS now elicited an L-LTP of S2 inputs that maintained at a higher level of synaptic potentiation for at least $4 \mathrm{~h}$ (tagged TBS, $165.1 \pm 5.3 \%$ of baseline at $4 \mathrm{~h}$ after weak TBS, $n=8$ slices/ 8 mice, $t_{(7)}=-12.207, p<0.001$, paired $t$ test; Fig.
1C). Not surprisingly, strong TBS application onto the S1 site evoked an endured L-LTP of S1 inputs (143.9 $\pm 3.3 \%$ of baseline at $4.5 \mathrm{~h}$ after strong TBS, $n=8$ slices $/ 8$ mice, $t_{(7)}=-6.941, p<$ 0.001 , paired $t$ test; Fig. $1 D$ ), which is consistent with our previous reports where strong TBS is delivered in the deep layer of the ACC (Chen et al., 2014a; Song et al., 2017). Importantly, the averaged magnitude of L-LTP induced by tagged TBS is comparable to that evoked by strong TBS (last 10 min of the recording, tagged TBS vs strong TBS: $168.2 \pm 5.3 \%$ of baseline vs $143.6 \pm 2.9 \%$ of baseline, $n=8$ slices $/ 8$ mice, $p=0.218$, one-way ANOVA followed by post hoc Fisher's LSD test; Fig. 1E), suggesting that, like the hippocampus (Frey and Morris, 1997), synaptic tagging-like phenomenon also exists in the adult ACC synapses. To examine whether strong TBS in S1 input could elicit a heterosynaptic potentiation of baseline synaptic responses in S2 input, we performed input specificity experiments. We applied a strong TBS to the S1 site but without delivering any tetanic stimulation on the $\mathrm{S} 2$ site and then monitored the LTP induction in both pathways for $3 \mathrm{~h}$ (Fig. $1 F$ ). We found that strong TBS alone could only produce significant L-LTP in S1 input $(165.3 \pm 3.9 \%$ of baseline at $3 \mathrm{~h}$ after strong 
A

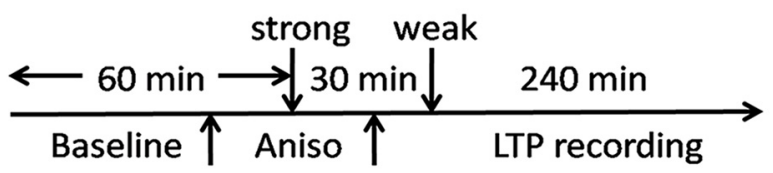

B

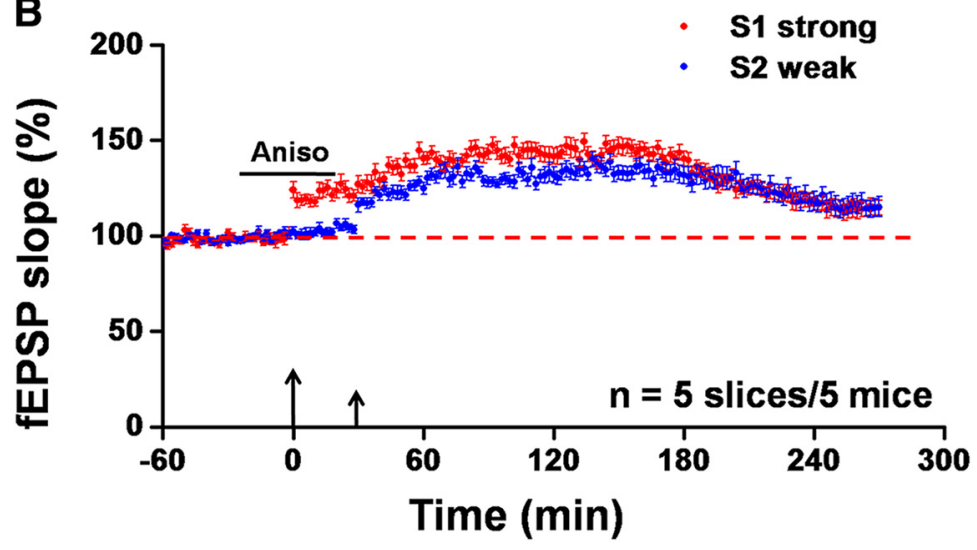

Figure 5. Synaptic tagging in the ACC requires new protein synthesis. $\boldsymbol{A}$, Schematic diagram of the recording procedure for this experiment. We applied the weak TBS protocol to the $S 2$ site at 30 min after strong TBS of the $S 1$ site in the presence of anisomycin (25 $\mu \mathrm{m}) . \boldsymbol{B}$, Pooled data of the fEPSP slope from all channels for both S1-strong and S2-weak inputs. Neither strong nor weak TBS can induce L-LTP ( $n=5$ slices/5 mice). Anisomycin blocked the occurrence of synaptic tagging in the ACC. Large arrow indicates starting point of strong TBS application; small arrow marks the time point of weak TBS delivery. Error bars in $\boldsymbol{B}$ represent SEM.

2014b; Song et al., 2017). Consistently, in the present study, we also found a clear enlargement of the response area following strong TBS of $\mathrm{S} 1$ site (Fig. $3 A, B$ ). We used a previously described mapping method (Kang et al., 2012; Liu et al., $2013 b)$ to analyze the spatial distribution of activated channels across the MED64 recording screen at both baseline state (Pre) and at $4.5 \mathrm{~h}$ after strong TBS at the S1 site (Post). Strong TBS resulted in a great increase in the responsive scope within the ACC slice (Fig. 3B). In total, 121 channels exhibited clear synaptic responses from 8 slices at the baseline state; and 24 new channels were recruited at $4.5 \mathrm{~h}$ after strong TBS. These data indicate that delivery of the strong TBS to the superficial layer (S1 stimulation site) of the ACC slice could similarly cause a network recruitment of newly activated responses compared with our previous report by conditioning deep layers in the ACC (Chen et al., 2014a). We next analyzed data after synaptic tagging (Fig. $3 C, D$ ). We found that there is no significant re-

TBS, $n=5$ slices/ 5 mice), without inducing any potentiation of the $\mathrm{S} 2$ baseline synaptic transmission $(102.2 \pm 4.7 \%$ of baseline at $3 \mathrm{~h}$ after strong TBS, $n=5$ slices $/ 5$ mice). This result further confirms the input independence of two pathways we stimulated in this study.

\section{Counting analysis of synaptic tagging in the ACC}

To present a more complete picture of synaptic tagging in the cortex, we performed in-depth analysis of the channel distributions of the ACC slices that pertain to three categories of LTP induction: L-LTP, E-LTP, and No-LTP. We defined L-LTPshowing channels as those exhibiting potentiated fEPSP that could sustain the whole recording period. E-LTP-showing channels in the ACC synapses were assigned as those where LTP gradually declines to the baseline with prolongation of the recording. No-LTP-showing channels are considered to have no significant synaptic potentiation after TBS delivery. According to this criterion, we analyzed the number of channels belonging to the three categories and calculated their induction ratios (percentage of LTP- or No-LTP-occurring channels vs all activated channels). We found that weak TBS alone resulted in more E-LTP- and No-LTP-showing channels than L-LTP-showing channels. Specifically, 30 channels of 8 ACC slices underwent L-LTP (L-LTP induction ratio: $18.8 \pm 3.2 \%$; Fig. $2 A$ ), but 54 channels failed to exhibit L-LTP (E-LTP: 20 channels, induction ratio: $21.3 \pm 4.4 \%$; Fig. 2C; No-LTP: 34 channels, induction ratio: $40.2 \pm 7.0 \%$; Fig. $2 E)$. By contrast, for tagged TBS, more activated channels exhibited L-LTP ( 59 channels of 8 slices, induction ratio: $62.0 \pm 6.6 \%$; Fig. $2 B$ ) with much less E-LTP-showing channels (16 channels, induction ratio: $14.7 \pm 3.2 \%$; Fig. $2 D)$ and No-LTP-showing channels (14 channels, induction ratio: $16.3 \pm 3.2 \%$; Fig. $2 F$ ). Therefore, our counting analysis revealed more precisely the nature of heterosynaptic plasticity in the ACC.

\section{No recruitment of new responses after synaptic tagging}

Previous work has demonstrated that strong TBS-induced L-LTP could recruit newly activated responses in the ACC (Chen et al., cruitment (a total of 133 channels vs 139 channels activated for the baseline and $4 \mathrm{~h}$ after the tagged L-LTP, $n=8$ slices $/ 8$ mice). These results suggest that synaptic tagging is only effective for temporal but not spatial changes of L-LTP in the ACC.

\section{Time window of synaptic tagging in the ACC}

Previous studies on synaptic tagging in the hippocampus show that weak conditioning stimulus-induced "tag setting" is activity dependent and the so-called "tag" has a life span of $<2 \mathrm{~h}$ (Frey and Morris, 1997, 1998; Sajikumar and Frey, 2004).Therefore, we are interested to see whether synaptic tagging still occur in the ACC when the interval between S1-strong and S2-weak is prolonged. We performed similar experiments with the exception that weak TBS was given to the S2 site either 1 or $2 \mathrm{~h}$ after the strong TBS was delivered to the S1 site (Fig. 4). We found that synaptic tagging persisted when the interval was $1 \mathrm{~h}$. Among the five slices analyzed, 30 channels $(59.1 \pm 9.1 \%)$ showed L-LTP, 11 channels $(17.5 \pm 5.4 \%)$ showed E-LTP, and five channels $(8.2 \pm$ $2.5 \%$ ) displayed No-LTP in S2 inputs. The averaged potentiation level of activated channels was $155.1 \pm 6.5 \%(n=5$ slices $/ 5$ mice, $t_{(4)}=-5.167, p=0.006$, paired $t$ test; Fig. $4 A$ ). Interestingly, when the interval was prolonged to $2 \mathrm{~h}$, synaptic tagging still could be observed in the S2 pathway ( $150.9 \pm 6.3 \%, n=6$ slices $/ 6$ mice, $t_{(5)}=-3.132, p=0.026$, paired $t$ test; Fig. $\left.4 B\right)$. Indeed, the magnitude of synaptic potentiation within last $10 \mathrm{~min}$ of the recording is similar among $30 \mathrm{~min}, 1 \mathrm{~h}$, and $2 \mathrm{~h}$ time gap $(30 \mathrm{~min}$ : $168.2 \pm 5.3 \%$ of baseline, $n=8$ slices $/ 8$ mice; 1 h: $155.4 \pm 6.6 \%$ of baseline, $n=5$ slices $/ 5$ mice; 2 h: $149.3 \pm 6.1 \%$ of baseline, $n=$ 6 slices/ 6 mice; Fig. 4C). However, a more detailed analysis of spatial distribution of LTP-showing channels revealed a marked decrease in the percentage of L-LTP-showing channels induced in the S2 pathway at $2 \mathrm{~h}$ interval compared with $30 \mathrm{~min}$ and $1 \mathrm{~h}$ interval (percentage of L-LTP channels: $30 \mathrm{~min}, 62.0 \pm 6.0 \% ; 1 \mathrm{~h}$, $59.1 \pm 6.1 \% ; 2$ h, $50.5 \pm 3.0 \%$; Fig. $4 D$ ). Thus, although the temporal progression of LTP could still be extended to a very long time, the spatial extent of L-LTP propagation is greatly shrinked with $2 \mathrm{~h}$ interval of synaptic tagging. 
Protein synthesis-dependent synaptic tagging in the ACC

It is well known that L-LTP requires novel protein synthesis (Costa-Mattioli et al., 2009; Chen et al., 2017), including ACC L-LTP (Chen et al., 2014b). We decided to test whether synaptic tagging also requires protein synthesis. We applied anisomycin $(25 \mu \mathrm{M})$, a selective protein synthesis inhibitor, $20 \mathrm{~min}$ before the delivery of strong TBS to the S1 site. The drug was washed out 20 min after strong TBS and a weak TBS was then given 10 min later. We monitored responses for another $4 \mathrm{~h}$ (Fig. 5A). Bath application of anisomycin during strong TBS blocked the induction of L-LTP in the S1-strong input (114.7 $\pm 3.9 \%$ of baseline at $4.5 \mathrm{~h}$ after strong TBS, $n=5$ slices $/ 5$ mice, $t_{(4)}=-0.187, p=0.861$, paired $t$ test; Fig. $5 B$ ). At S2 site, synaptic tagging was also blocked (115.3 $\pm 5.3 \%$ of baseline at $4 \mathrm{~h}$ after weak TBS, $n=5$ slices $/ 5$ mice, $t_{(4)}=-0.151, p=0.887$, paired $t$ test; Fig. $5 B$ ). Thus, these observations confirmed the de novo protein synthesis-dependent nature of synaptic tagging in the ACC.

\section{Loss of synaptic tagging after} tail amputation

Previous studies demonstrate that digit or tail amputation triggers long-lasting plastic alterations in the ACC (Wei et al., 1999; Wei and Zhuo, 2001; Kang et al., 2012). We wanted to test whether synaptic tagging is also affected. After distal tail amputation, we found that synaptic tagging was completely blocked (Fig. 6A,B). Neither strong TBS nor weak TBS was able to elicit any significant L-LTP at the end of the recording period $(\mathrm{S} 1: 112.7 \pm 2.8 \%$ of baseline at $4.5 \mathrm{~h}$ after strong TBS, $n=7$ slices $/ 7$ mice, $t_{(6)}=-2.235, p=0.067$, paired $t$ test; S2: $113.0 \pm 3.1 \%$ of baseline at $4 \mathrm{~h}$ after weak TBS, $n=7$ slices/ 7 mice, $t_{(6)}=-1.379, p=0.217$, paired $t$ test; Figure $6 B$ ). Most of the activated channels are classified as either E-LTP- (S1: 29 channels, induction ratio: $41.4 \pm 5.1 \%$; S2: 37 channels, induction ratio: $36.1 \pm$ $5.3 \%$ ) or No-LTP-showing (S1: 12 channels, induction ratio: $16.6 \pm 4.7 \%$; S2: 32 channels, induction ratio: $33.9 \pm 4.7 \%$ ) category. Figure 7 presents the individual channel data of the fEPSP slope pertaining to the three categories for both S1-strong $(A, C, E)$ and S2-weak $(B, D, F)$ afferent pathways. Furthermore, we found that tail amputation blocked the recruitment of new channels elicited by strong TBS (Fig. $6 C, D)$. These findings suggest that peripheral injury also abolished the re-
A

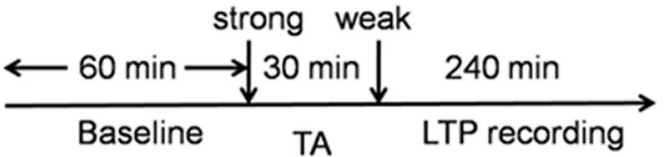

B
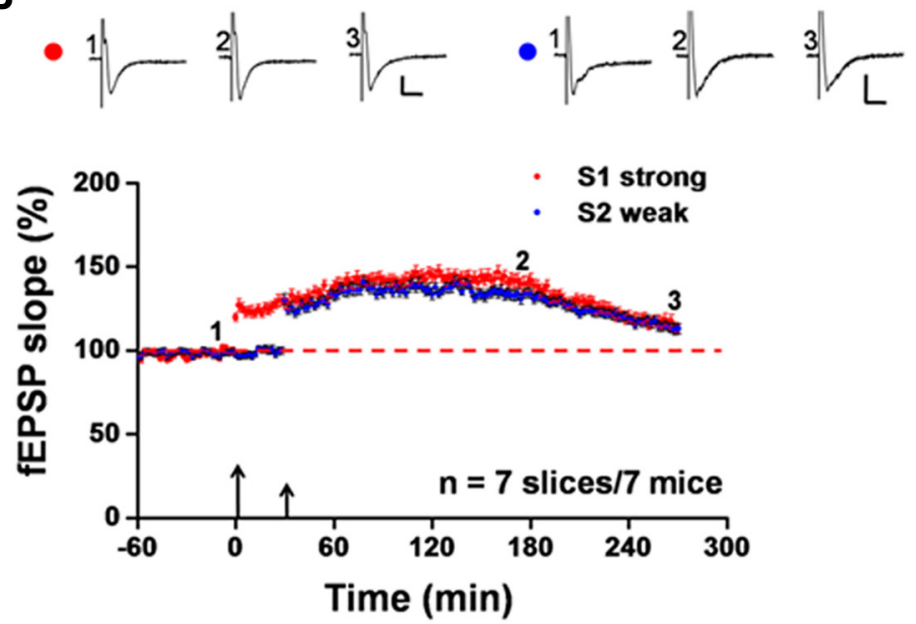

C TBS: $\mathbf{S 1 - s t r o n g ~ ( ~} \mathrm{n}=7$ slices $/ 7$ mice)
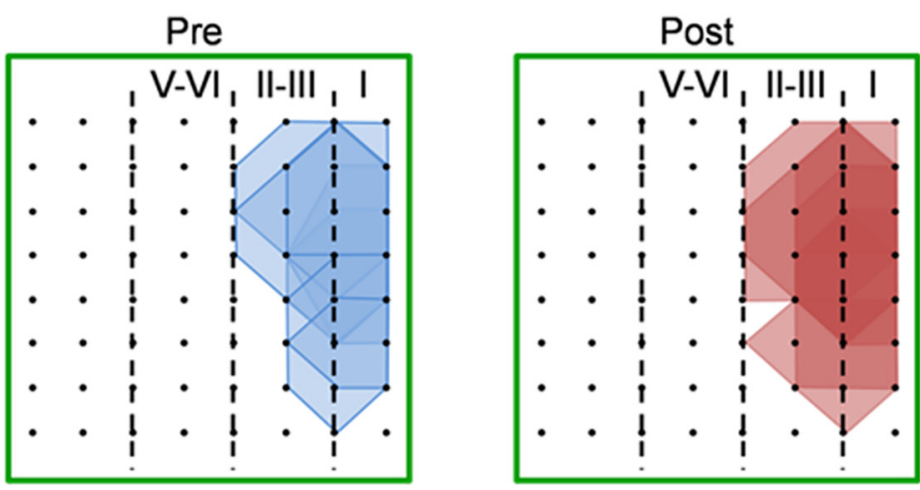

D TBS: S2-weak ( $\mathbf{n}=7$ slices/7 mice)
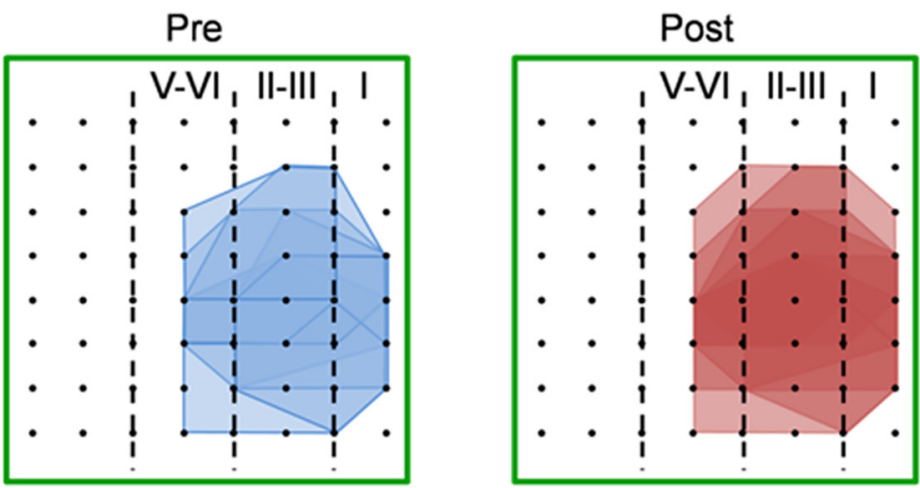

Figure 6. L L L L this experiment. We applied the weak TBS protocol to the $S 2$ site at 30 min after strong TBS of the $S 1$ site in the ACC slices taken from tail-amputated mice (2 weeks experience). TA, Tail amputation. B, Pooled data of the fEPSP slope from all channels for both S1-strong and S2-weak inputs. Neither strong nor weak TBS can induce L-LTP ( $n=7$ slices/7 mice), indicating the loss of cortical synaptic tagging after amputation. Inset, Representative fEPSP traces taken at the time points indicated by numbers in the graph. Calibration: $100 \mu \mathrm{V}, 10 \mathrm{~ms}$. Large arrow indicates starting point of strong TBS application; small arrow marks the time point of weak TBS delivery. Error bars represent SEM. C, Polygonal diagrams of the channels that were activated in the baseline state (blue, pre) and at $4.5 \mathrm{~h}$ after strong TBS of the S1 site (red, post) in seven slices from seven tail-amputated mice. Black dots represent the 64 channels in the MED64. Vertical lines indicate the layers in the ACC slice. D, Pooled data of the spatial analysis similar as in C but for the weak TBS of the $S 2$ site ( $n=7$ slices $/ 7$ mice). Tail amputation blocked strong TBS-induced network potentiation in the ACC. 

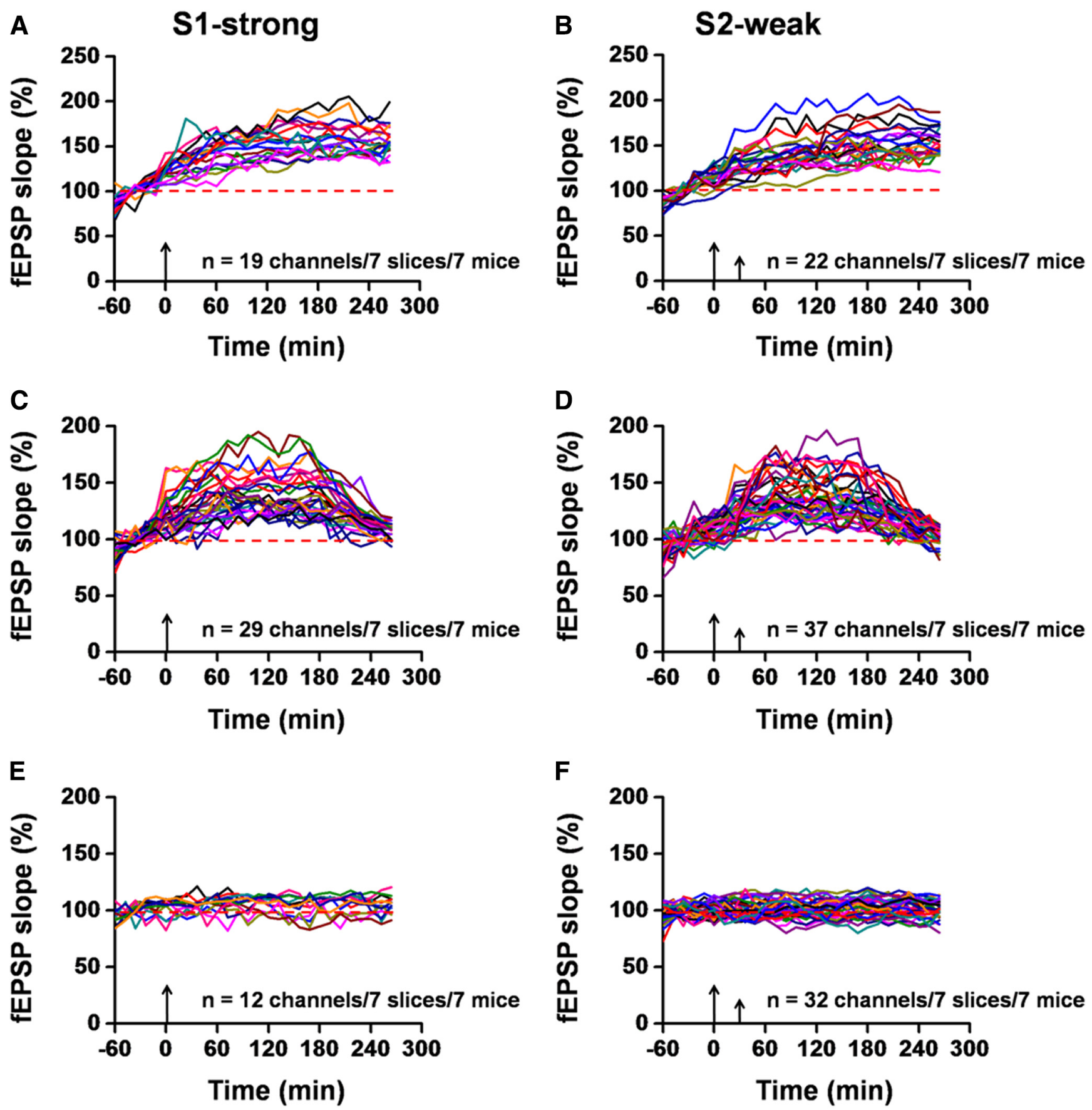

Figure 7. Individual data presentation of abolished synaptic tagging after tail amputation. $A, C, E$, Individual data of L-LTP-, E-LTP-and No-LTP-showing channels for the S1 input of the ACC slices obtained from tail-amputated mice. In total, 19 channels underwent L-LTP in response to the strong TBS, whereas 29 channels showed E-LTP. There were 12 channels that did not exhibit any potentiation ( $n=7$ slices/7 mice). $\boldsymbol{B}, \boldsymbol{D}, \boldsymbol{F}$, Individual data of L-LTP-, E-LTP-, and No-LTP-showing channels for the S2 input. Among the seven slices analyzed, 22,37 , and 32 channels showed L-LTP, E-LTP, and No-LTP, respectively. Tail amputation reduced the induction probability of L-LTP at both S1 and S2 inputs. Large arrows indicate starting point of strong TBS application; small arrows mark the time point of weak TBS delivery.

cruitment of local responses by strong TBS, possibly by the occlusion mechanism.

Occlusion of L-LTP after amputation: a possible mechanism for loss of synaptic tagging

It is believed that cortical synaptic plasticity shares some common mechanisms with chronic pain (Zhuo, 2008, 2015; Bliss et al., 2016). As a line of supportive evidence, we previously reported that the induction of cingulate L-LTP could be fully occluded by neuropathic pain (Li et al., 2010). Based on these observations, we hypothesized that tail amputation might similarly occlude the induction of strong TBS-elicited L-LTP. The loss of L-LTP leads to the lack of newly synthesized PRPs that could otherwise be captured by the weakly tetanized S2 input, thus preventing synaptic tagging to develop in amputated ACC slices. To test this, we investigated the effect of tail amputation on the LTP inducibility elicited by strong TBS alone applied into the superficial layer of the ACC slices. As expected, delivery of a single strong TBS into the S1 site only induced decremental LTP in the ACC slices (105.0 $\pm 4.0 \%$ of 
baseline at $4 \mathrm{~h}$ after strong TBS, $n=6$ slices $/ 6$ mice, $t_{(5)}=-0.775, p=0.473$, paired $t$ test; Fig. $8 A, B)$.

\section{Discussion}

ACC is an important forebrain structure critically involved in a variety of higher brain functions, such as pain perception, memory storage, and emotional processing. Synaptic plasticity in the ACC has been proved to be the key cellular/synaptic substrate for chronic pain, fear, and anxiety (Zhao et al., 2005; Koga et al., 2015; Zhuo, 2016). In the present study, we report that synaptic tagging, a heterosynaptic form of plasticity, exists in adult excitatory synapses of the ACC. This form of synaptic tagging is lost in animals with peripheral distal tail amputation, indicating that it may contribute to pathological changes on the brain after injury. In addition, we demonstrate that a single weak TBS into the deep layer of the ACC mainly results in an E-LTP that decays within $3 \mathrm{~h}$, and a stronger TBS of superficial layer in the ACC produces L-LTP.
A
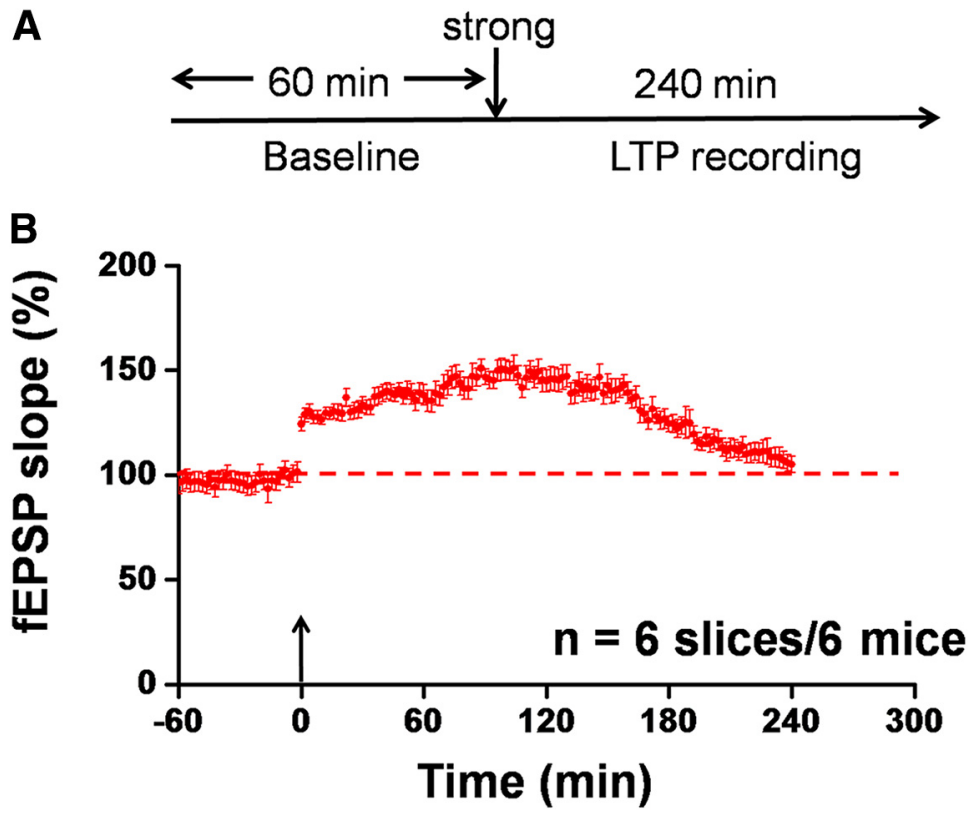

Figure 8. Tail amputation occludes strong TBS-evoked L-LTP in the ACC. $A$, Schematic diagram of the recording procedure for this experiment. We applied the strong TBS protocol to the $S 1$ site in the ACC slices obtained from amputated mice (2 weeks experience). $\boldsymbol{B}$, Pooled data of the fEPSP slope from all channels. Strong TBS-induced L-LTP was occluded by amputation ( $n=6$ slices/6 mice). Large arrow indicates starting point of strong TBS application. Error bars represent SEM.

\section{E-LTP in the ACC and hippocampus}

In the present study, we find that weak TBS induces declining E-LTP in the ACC that lasts $\sim 2-3 \mathrm{~h}$. In the hippocampus, the time course of E-LTP usually lasts for 1-2 h (Alarcon et al., 2006; Ramachandran and Frey, 2009; Shires et al., 2012; Sharma et al., 2017). One possible explanation is that different induction protocols were used. In the hippocampus, high-frequency tetanic stimulation is used, whereas TBS is used in the ACC. Our present study provides another useful method to explore possible mechanistic difference between hippocampal and cortical synapses.

Synaptic tagging: a heterosynaptic form of L-LTP in the ACC Previous electrophysiological studies in the hippocampus suggest that two different pathways in the CA1 region can interact in an associative manner, so that a weakly tetanized synaptic input could paradoxically exhibit L-LTP if the weak tetanus is preceded or followed by a strong tetanus within a finite time window (Frey and Morris, 1997, 1998). This phenomenon has been well explained by the synaptic tagging theory, which proposes that the weak tetanus generates a tag being capable of capturing the newly synthesized PRPs triggered by the strong tetanus (Reymann and Frey, 2007; Redondo and Morris, 2011). Many studies have been reported about the basic mechanisms and behavioral relevance of synaptic tagging in the hippocampus (Young et al., 2006; Ramachandran and Frey, 2009; Sajikumar and Korte, 2011; Dasgupta et al., 2017). However, it is unclear whether synaptic tagging is unique in learning-related hippocampal synapses. In this study, we first demonstrate that heterosynaptic interactions could also occur in the adult mouse ACC synapses. A weak TBS, that normally causes E-LTP or No-LTP, induces L-LTP in most of the activated channels when it is given $30 \mathrm{~min}$ or $1 \mathrm{~h}$ after a strong TBS applied to a separate pathway. Furthermore, this heterosynaptic L-LTP is dependent on the de novo protein synthesis. By using the multiple recording system, we demonstrate that such tagging can occur at multiple synapses within the circuit, suggesting that the persistence of synaptic changes in the ACC could be equally influenced by the previous history of neuronal activity in the same area. Considering the importance of ACC synapses in pain perception, fear, and anxiety (Bliss et al., 2016; Zhuo, 2016; Chen et al., 2018; Keum et al., 2018; Sellmeijer et al., 2018), these findings raise the possibility that synaptic tagging may have a more general physiological function in the brain. It will be of great interest for a future study to further elucidate the molecular mechanisms of this newly identified cortical synaptic tagging and to dissect its behavioral relevance.

\section{Different forms of synaptic plasticity in the adult ACC}

ACC synapses of adult animals are highly plastic. Cumulative evidence demonstrates that two major form of LTP can be detected in ACC synapses: NMDA receptor-dependent postsynaptic LTP (post-LTP; Zhao et al., 2005), and kainate receptor-dependent presynaptic LTP (Koga et al., 2015). The present study extends the discovery of LTP, especially post-LTP, into both E-LTP and L-LTP. Application of a single weak TBS into the deep layer of the ACC mainly results in a E-LTP that decays gradually after conditioning stimulation. However, delivery of a stronger TBS protocol into the superficial layer produces a much longer form of persistent L-LTP that can be maintained for $4.5 \mathrm{~h}$. More importantly, we demonstrate that synaptic tagging, which is originally discovered in hippocampal synapses, also exists in the ACC. Two separate inputs can interact with each other in a heterosynaptic manner, leading to the interpathway transfer of L-LTP. These results indicate that both homosynaptic and heterosynaptic LTP occur in the ACC, providing distinct basic mechanisms for different physiological and pathological functions of ACC.

\section{Functional significance of synaptic tagging}

Excitatory synaptic transmission in the ACC is significantly enhanced in various animal models of pain (Zhao et al., 2006; Xu et al., 2008). Injury-induced LTP-like synaptic enhancement occludes the induction of cingulate LTP by electrical conditioning stimulus (Zhao et al., 2006; Li et al., 2010; Koga et al., 2015). 
According to this theory, we sought to determine whether the synaptic tagging in the ACC is equally vulnerable to tail amputation-induced abnormal pain. We found that a 2 week experience of tail amputation ablated the associative interactions between S1-strong and S2-weak pathway in the mouse ACC slices. One possible explanation for this result might derive from the observation that application of strong TBS alone failed to induce L-LTP in the amputated ACC slices. Loss of strong TBSevoked L-LTP due to occlusion results in less available PRPs that could be used by weak TBS-induced tags, thus leading to the failure of heterosynaptic facilitation of L-LTP after amputation. Interestingly, strong tetanization-induced network recruitment of new activated channels is also blocked by amputation. Collectively, the present study provides the first demonstration of the effect of tissue amputation on LTP inducibility and associativity in the cerebral cortex, which, combined with previous observations on cortical LTD (Kang et al., 2012; Liu and Zhuo, 2014b), expands our understanding of the possible synaptic pathophysiology of phantom pain.

In summary, we report a novel form of heterosynaptic plasticity in the adult mouse neocortex, by showing the occurrence of synaptic tagging between two different afferent inputs in the ACC slices in vitro. This newly identified cortical synaptic tagging is dependent on the de novo synthesis of new proteins. In addition, peripheral tail amputation abolishes the heterosynaptic tagging in the ACC, which might provide a novel way by which peripheral injury elicits long-lasting maladaptive alterations in synaptic transmission and function in the CNS.

\section{References}

Alarcon JM, Barco A, Kandel ER (2006) Capture of the late phase of longterm potentiation within and across the apical and basilar dendritic compartments of CA1 pyramidal neurons: synaptic tagging is compartment restricted. J Neurosci 26:256-264. CrossRef Medline

Bliss TV, Collingridge GL (2013) Expression of NMDA receptor-dependent LTP in the hippocampus: bridging the divide. Mol Brain 6:5. CrossRef Medline

Bliss TV, Collingridge GL, Kaang BK, Zhuo M (2016) Synaptic plasticity in the anterior cingulate cortex in acute and chronic pain. Nat Rev Neurosci 17:485-496. CrossRef Medline

Chen PB, Kawaguchi R, Blum C, Achiro JM, Coppola G, O'Dell TJ, Martin KC (2017) Mapping gene expression in excitatory neurons during hippocampal late-phase long-term potentiation. Front Mol Neurosci 10:39. CrossRef Medline

Chen T, O’Den G, Song Q, Koga K, Zhang MM, Zhuo M (2014a) Adenylyl cyclase subtype 1 is essential for late-phase long term potentiation and spatial propagation of synaptic responses in the anterior cingulate cortex of adult mice. Mol Pain 10:65. CrossRef Medline

Chen T, Lu JS, Song Q, Liu MG, Koga K, Descalzi G, Li YQ, Zhuo M (2014b) Pharmacological rescue of cortical synaptic and network potentiation in a mouse model for fragile X syndrome. Neuropsychopharmacology 39: 1955-1967. CrossRef Medline

Chen T, Taniguchi W, Chen QY, Tozaki-Saitoh H, Song Q, Liu RH, Koga K, Matsuda T, Kaito-Sugimura Y, Wang J, Li ZH, Lu YC, Inoue K, Tsuda M, Li YQ, Nakatsuka T, Zhuo M (2018) Top-down descending facilitation of spinal sensory excitatory transmission from the anterior cingulate cortex. Nat Commun 9:1886. CrossRef Medline

Chiou CS, Huang CC, Liang YC, Tsai YC, Hsu KS (2012) Impairment of long-term depression in the anterior cingulate cortex of mice with bone cancer pain. Pain 153:2097-2108. CrossRef Medline

Costa-Mattioli M, Sossin WS, Klann E, Sonenberg N (2009) Translational control of long-lasting synaptic plasticity and memory. Neuron 61:10-26. CrossRef Medline

Dasgupta A, Baby N, Krishna K, Hakim M, Wong YP, Behnisch T, Soong TW, Sajikumar S (2017) Substance P induces plasticity and synaptic tagging/ capture in rat hippocampal area CA2. Proc Natl Acad Sci U S A 114: E8741-E8749. CrossRef Medline

Flor H, Nikolajsen L, Staehelin Jensen T (2006) Phantom limb pain: a case of maladaptive CNS plasticity? Nat Rev Neurosci 7:873-881. CrossRef Medline

Frankland PW, Bontempi B, Talton LE, Kaczmarek L, Silva AJ (2004) The involvement of the anterior cingulate cortex in remote contextual fear memory. Science 304:881-883. CrossRef Medline

Frey U, Morris RG (1997) Synaptic tagging and long-term potentiation. Nature 385:533-536. CrossRef Medline

Frey U, Morris RG (1998) Weak before strong: dissociating synaptic tagging and plasticity-factor accounts of late-LTP. Neuropharmacology 37:545552. CrossRef Medline

Ishikawa Y, Horii Y, Tamura H, Shiosaka S (2008) Neuropsin (KLK8)dependent and -independent synaptic tagging in the schaffer-collateral pathway of mouse hippocampus. J Neurosci 28:843-849. CrossRef Medline

Kang SJ, Liu MG, Chen T, Ko HG, Baek GC, Lee HR, Lee K, Collingridge GL, Kaang BK, Zhuo M (2012) Plasticity of metabotropic glutamate receptor-dependent long-term depression in the anterior cingulate cortex after amputation. J Neurosci 32:11318-11329. CrossRef Medline

Keum S, Kim A, Shin JJ, Kim JH, Park J, Shin HS (2018) A missense variant at the Nrxn3 locus enhances empathy fear in the mouse. Neuron 98:588 601. CrossRef Medline

Ko HG, Choi JH, Park DI, Kang SJ, Lim CS, Sim SE, Shim J, Kim JI, Kim S, Choi TH, Ye S, Lee J, Park P, Kim S, Do J, Park J, Islam MA, Kim HJ, Turck CW, Collingridge GL, et al. (2018) Rapid turnover of cortical NCAM1 regulates synaptic reorganization after peripheral nerve injury. Cell Rep 22:748-759. CrossRef Medline

Koga K, Descalzi G, Chen T, Ko HG, Lu J, Li S, Son J, Kim T, Kwak C, Huganir RL, Zhao MG, Kaang BK, Collingridge GL, Zhuo M (2015) Coexistence of two forms of LTP in ACC provides a synaptic mechanism for the interactions between anxiety and chronic pain. Neuron 85:377-389. CrossRef Medline

Koga K, Yao I, Setou M, Zhuo M (2017) SCRAPPER selectively contributes to spontaneous release and presynaptic long-term potentiation in the anterior cingulate cortex. J Neurosci 37:3887-3895. CrossRef Medline

Li Q, Navakkode S, Rothkegel M, Soong TW, Sajikumar S, Korte M (2017) Metaplasticity mechanisms restore plasticity and associativity in an animal model of Alzheimer's disease. Proc Natl Acad Sci U S A 114:55275532. CrossRef Medline

Li XY, Ko HG, Chen T, Descalzi G, Koga K, Wang H, Kim SS, Shang Y, Kwak C, Park SW, Shim J, Lee K, Collingridge GL, Kaang BK, Zhuo M (2010) Alleviating neuropathic pain hypersensitivity by inhibiting PKMzeta in the anterior cingulate cortex. Science 330:1400-1404. CrossRef Medline

Liu MG, Zhuo M (2014a) No requirement of TRPV1 in long-term potentiation or long-term depression in the anterior cingulate cortex. Mol Brain 7:27. CrossRef Medline

Liu MG, Zhuo M (2014b) Loss of long-term depression in the insular cortex after tail amputation in adult mice. Mol Pain 10:1. CrossRef Medline

Liu MG, Koga K, Guo YY, Kang SJ, Collingridge GL, Kaang BK, Zhao MG, Zhuo M (2013a) Long-term depression of synaptic transmission in the adult mouse insular cortex in vitro. Eur J Neurosci 38:3128-3145. CrossRef Medline

Liu MG, Kang SJ, Shi TY, Koga K, Zhang MM, Collingridge GL, Kaang BK, Zhuo M (2013b) Long-term potentiation of synaptic transmission in the adult mouse insular cortex: multielectrode array recordings. J Neurophysiol 110:505-521. CrossRef Medline

Park P, Sanderson TM, Amici M, Choi SL, Bortolotto ZA, Zhuo M, Kaang BK, Collingridge GL (2016) Calcium-permeable AMPA receptors mediate the induction of the protein kinase A-dependent component of long-term potentiation in the hippocampus. J Neurosci 36:622-631. CrossRef Medline

Ramachandran B, Frey JU (2009) Interfering with the actin network and its effect on long-term potentiation and synaptic tagging in hippocampal CA1 neurons in slices in vitro. J Neurosci 29:12167-12173. CrossRef Medline

Redondo RL, Morris RG (2011) Making memories last: the synaptic tagging and capture hypothesis. Nat Rev Neurosci 12:17-30. CrossRef Medline

Reymann KG, Frey JU (2007) The late maintenance of hippocampal LTP: requirements, phases, "synaptic tagging", "late-associativity" and implications. Neuropharmacology 52:24-40. CrossRef Medline

Rogerson T, Cai DJ, Frank A, Sano Y, Shobe J, Lopez-Aranda MF, Silva AJ (2014) Synaptic tagging during memory allocation. Nat Rev Neurosci 15:157-169. CrossRef Medline 
Sajikumar S, Frey JU (2004) Late-associativity, synaptic tagging, and the role of dopamine during LTP and LTD. Neurobiol Learn Mem 82:12-25. CrossRef Medline

Sajikumar S, Korte M (2011) Metaplasticity governs compartmentalization of synaptic tagging and capture through brain-derived neurotrophic factor (BDNF) and protein kinase $\mathrm{M} \zeta(\mathrm{PKM} \zeta)$. Proc Natl Acad Sci U S A 108:2551-2556. CrossRef Medline

Sellmeijer J, Mathis V, Hugel S, Li XH, Song Q, Chen QY, Barthas F, Lutz PE, Karatas M, Luthi A, Veinante P, Aertsen A, Barrot M, Zhuo M, Yalcin I (2018) Hyperactivity of anterior cingulate cortex areas 24a/24b drives chronic pain-induced anxiodepressive-like consequences. J Neurosci 38: 3102-3115. CrossRef Medline

Sharma M, Shetty MS, Arumugam TV, Sajikumar S (2015) Histone deacetylase 3 inhibition re-establishes synaptic tagging and capture in aging through the activation of nuclear factor kappa B. Sci Rep 5:16616. CrossRef Medline

Sharma M, Razali NB, Sajikumar S (2017) Inhibition of G9a/GLP complex promotes long-term potentiation and synaptic tagging/capture in hippocampal CA1 pyramidal neurons. Cereb Cortex 27:3161-3171. CrossRef Medline

Shires KL, Da Silva BM, Hawthorne JP, Morris RG, Martin SJ (2012) Synaptic tagging and capture in the living rat. Nat Commun 3:1246. CrossRef Medline

Song Q, Zheng HW, Li XH, Huganir RL, Kuner T, Zhuo M, Chen T (2017) Selective phosphorylation of AMPA receptor contributes to the network of long-term potentiation in the anterior cingulate cortex. J Neurosci 37:8534-8548. CrossRef Medline

Takeuchi T, Duszkiewicz AJ, Morris RG (2014) The synaptic plasticity and memory hypothesis: encoding, storage and persistence. Philos Trans R Soc Lond B Biol Sci 369:20130288. CrossRef Medline

Wang SH, Redondo RL, Morris RG (2010) Relevance of synaptic tagging and capture to the persistence of long-term potentiation and everyday spatial memory. Proc Natl Acad Sci U S A 107:19537-19542. CrossRef Medline
Wei F, Zhuo M (2001) Potentiation of sensory responses in the anterior cingulate cortex following digit amputation in the anaesthetised rat. J Physiol 532:823-833. CrossRef Medline

Wei F, Li P, Zhuo M (1999) Loss of synaptic depression in mammalian anterior cingulate cortex after amputation. J Neurosci 19:9346-9354. CrossRef Medline

Xu H, Wu LJ, Wang H, Zhang X, Vadakkan KI, Kim SS, Steenland HW, Zhuo M (2008) Presynaptic and postsynaptic amplifications of neuropathic pain in the anterior cingulate cortex. J Neurosci 28:7445-7453. CrossRef Medline

Young JZ, Nguyen PV (2005) Homosynaptic and heterosynaptic inhibition of synaptic tagging and capture of long-term potentiation by previous synaptic activity. J Neurosci 25:7221-7231. CrossRef Medline

Young JZ, Isiegas C, Abel T, Nguyen PV (2006) Metaplasticity of the latephase of long-term potentiation: a critical role for protein kinase A in synaptic tagging. Eur J Neurosci 23:1784-1794. CrossRef Medline

Zhao MG, Toyoda H, Lee YS, Wu LJ, Ko SW, Zhang XH, Jia Y, Shum F, Xu H, Li BM, Kaang BK, Zhuo M (2005) Roles of NMDA NR2B subtype receptor in prefrontal long-term potentiation and contextual fear memory. Neuron 47:859-872. CrossRef Medline

Zhao MG, Ko SW, Wu LJ, Toyoda H, Xu H, Quan J, Li J, Jia Y, Ren M, Xu ZC, Zhuo M (2006) Enhanced presynaptic neurotransmitter release in the anterior cingulate cortex of mice with chronic pain. J Neurosci 26:89238930. CrossRef Medline

Zhuo M (2008) Cortical excitation and chronic pain. Trends Neurosci 31: 199-207. CrossRef Medline

Zhuo M (2012) Cortical depression and potentiation: basic mechanisms for phantom pain. Exp Neurobiol 21:129-135. CrossRef Medline

Zhuo M (2015) Targeting injury-related synaptic plasticity for the treatment of chronic pain. Curr Pharm Des 21:914-919. CrossRef Medline

Zhuo M (2016) Neural mechanisms underlying anxiety-chronic pain interactions. Trends Neurosci 39:136-145. CrossRef Medline 